\title{
PAPER
}

\section{Intraventricular monitoring for temporal lobe epilepsy: report on technique and initial results in eight patients}

\author{
J K Song, B Abou-Khalil, P E Konrad
}

J Neurol Neurosurg Psychiatry 2003;74:561-565

See end of article for authors' affiliations

................

Correspondence to:

Dr P E Konrad, Department

of Neurosurgery, Room

T-4224; MCN, Vanderbilt

University Medical Center,

Nashville, TN 37232,

USA;

peter.konrad@vanderbilt.edu

Received 8 April 2002

Accepted in final revised

form

14 January 2003

\begin{abstract}
Objective and importance: Resective surgery is an effective treatment for refractory temporal lobe epilepsy. In difficult cases, invasive monitoring may be needed to precisely lateralise and localise seizure foci of mesial temporal origin. The authors present a modified technique for image guided, endoscopic placement of an intraventricular electrode array (IVE) that abuts the amygdalo-hippocampal complex.

Methods: Eight patients with suspected mesial temporal lobe epilepsy had placement of an IVE in conjunction with other invasive electrodes. Seven of these patients also had subdural grid or strip electrodes and four had foramen ovale electrodes. Frameless image guidance was used to place a custom 10-contact depth electrode through a rigid neuroendoscope within the atrium of the lateral ventricle. Once proper orientation towards the temporal horn was confirmed, the IVE array was advanced into the temporal horn to the temporal tip. The endoscope was removed and electrode placement was confirmed through an intraoperative lateral skull radiograph and on visual inspection at the time of resection in two cases.

Results: The IVE was crucial for localisation in one patient and helped localisation in four others. Surgery was offered to seven patients. The only serious complication of IVE placement was a thalamic contusion presumably from an errant electrode tip. One electrode was inadvertently placed into the frontal horn. There were no deaths and no permanent morbidity associated with the procedure.

Conclusion: Endoscopically placed temporal horn, intraventricular electrodes provide an alternative to transcortical depth electrode placement. The technique hopefully can avoid complications associated with multiple depth electrode placements, especially when bilateral amygdalo-hippocampal electrical recordings are desired, although there may be a steep learning curve.
\end{abstract}

$\mathrm{N}$ umerous techniques have been used to record the epileptogenic zone non-invasively, semi-invasively, and invasively. Routine non-invasive methods such as scalp EEG or positron emission tomography with F-fluorodeoxyglucose (FDG-PET) at times cannot provide sufficient functional information to localise seizures. Semiinvasive monitoring methods include foramen ovale electrodes and epidural peg electrodes. Recently, in an attempt to locate electrodes closer to the hippocampus, one report even describes an intra-arterial catheter for EEG recording. ${ }^{1}$ Despite these comparatively low risk and semi-invasive techniques, accurate and precise seizure localisation cannot always be determined. In a study by Behrens et al, ${ }^{2}$ seizures in 160 epilepsy patients could not be localised with non-invasive monitoring. However, with invasive monitoring, 143 of 160 patients were offered resective surgery. Invasive methods for epilepsy monitoring include subdural strips or grid electrodes or depth electrodes. Spencer et al report that subdural electrodes were $20 \%$ less sensitive than depth electrodes in detecting seizures originating from the hippocampus in their series. ${ }^{3}$ However, depth electrodes, in conjunction with strip electrodes, are especially useful in evaluating temporal lobe seizures. ${ }^{2}$

Ideally electrodes should be close to the source of the seizure, and placed on each side of the seizure focus. If a phase reversal of the electrical waveform is noted between two electrodes, the electrodes are thought to surround the dipole source of the signal. ${ }^{4}$ Thus, when determining the location of electrographic seizure onset, dipole localisation may be an indication for resective surgery. As seizure onset in temporal lobe epilepsy may or may not occur from the amygdalohippocampal structures, locating the dipole may be easier when one set of electrodes lies within the temporal horn. This allows dipole localisation to be made with simultaneous recording from mesial, inferior, or lateral temporal structures.

Although the technique of stereotactic depth electrode placement is most accurate in locating electrodes within the hippocampus, some potential safety concerns exist. Traditional depth electrodes are known to be associated with risk of vascular injury and also may cause recording abnormalities secondary to the passage of the electrode through the parenchyma of the temporal lobe..$^{5-7}$ As hippocampal depth electrodes are typically placed bilaterally, damage to the nonresected hippocampus from passage of the electrode into the parenchyma of the hippocampus can occur.

An alternative to transcortical depth electrode placement is the placement of a temporal horn, intraventricular electrode. This idea is not novel-review of the literature reveals that Blume et $\mathrm{al}^{8}$ mention a similar method for intraventricular recording but do not go into detail describing the procedure. Freehand placement of intraventricular electrodes was described in 1989 by Polkey et al, ${ }^{1}$ in which he noted the value of recording hippocampal discharges in selection of patients for limited amygdalo-hippocampectomy compared with en bloc temporal lobectomy. His procedure was performed at the time of resection. McBride $e t ~ a l^{10}$ later described the findings associated with this type of recording and discussed the lack of predictability of intraoperative recordings on success of the temporal lobe resection. In contrast, we describe the methodology and results of an endoscopically placed intraventricular electrode array for presurgical monitoring of temporal lobe

Abbreviations: $\mathrm{CT}$, computed tomography; IVE, intraventricular electrode 


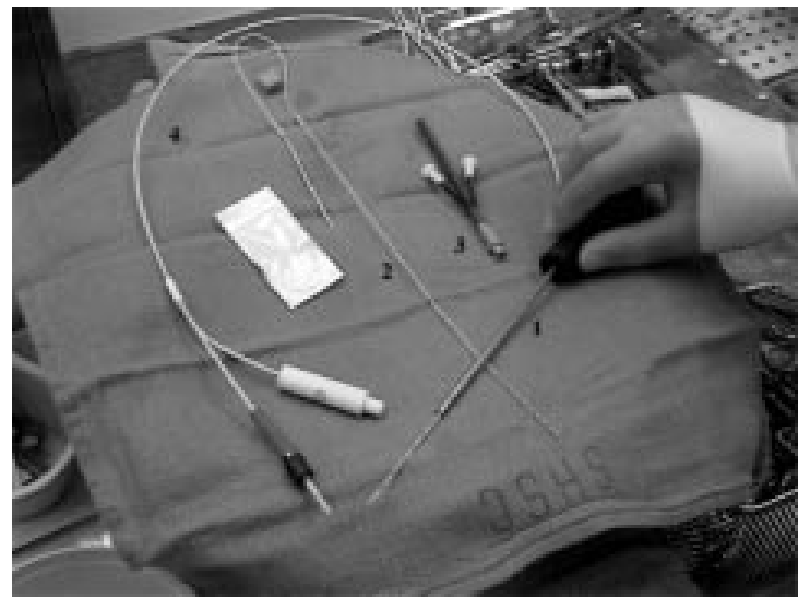

Figure 1 Apparatus for placement of intraventricular electrode array. (1) Rigid neuroendoscope with intraventricular electrode. (2) Intraventricular electrode array. (3) Peel away sheath. (4) Video/illumination system.

epilepsy and illustrate some potentially useful observations in localisation of seizure onset.

\section{METHODS}

Eight patients with suspected mesial temporal lobe epilepsy that was medically intractable and of uncertain laterality were chosen for surgery. After informed consent, each patient underwent some combination of bilateral intraventricular recording alone or with subdural grids/strips, sphenoidal, or foramen ovale electrodes. Their age ranged from 18-46 years; there were four women and four men in the study. None had prior invasive evaluation or surgical resection for epilepsy. One patient had prior resection of a low grade temporal glioma 18 years previously. Before intraventricular electrode placement, each patient underwent a preoperative computed tomographic (CT) scan with fiducial markers for intraoperative image guidance (Viewpoint; Picker International, Highland Heights, OH, USA). This aided in defining the trajectory necessary for the burr hole insertion of the endoscope through the occipital lobe into the atrium of the lateral ventricle. Then the electrode was guided into the temporal horn through the centre channel of the endoscope.

The apparatus used is shown in figure 1 . The electrode is a custom made 10 contact linear depth electrode (model SD-10P-32) produced by Ad-Tech Medical Instrument Corporation (Racine, WI, USA). It has an overall length of $390 \mathrm{~mm}$ and a diameter of $1.0 \mathrm{~mm}$. There are 10 platinum contacts spaced over $50 \mathrm{~mm}$, each $2 \mathrm{~mm}$ in length and spaced $5.5 \mathrm{~mm}$ apart. The proximal end of the electrode has 10 leads for connection to recording equipment and there is a central stylet. The video endoscopic system (model 2233-005; Medtronic PS Medical, Goleta, CA, USA) contains a central channel for passage of the electrode. In particular, the endoscope used is 130 $\mathrm{mm}$ in length with a $4.2 \mathrm{~mm}$ outer diameter and a $2.15 \mathrm{~mm}$ working channel together with separate light and irrigation lumens. A peel away sheath with obturator (Cook Catheter Corporation, Bloomington, IN, USA) is used as a blunt cannula for initial insertion of the endoscope.

\section{Technique}

The patient is given general endotracheal anaesthesia, placed in the prone position, and the head is fixed in a skull clamp. Registration of fiducial markers is then performed. Entry and target points were selected for each side by identifying the atrium of the lateral ventricle (target) and a linear trajectory from the scalp (entry point) so as to place the endoscope in direct view of the ostium of the temporal horn. Firstly, a vertical, paramedian

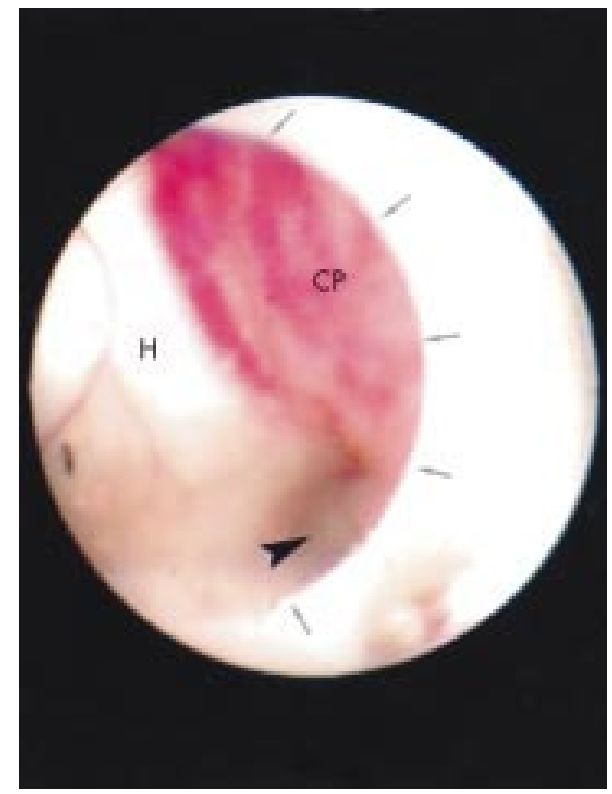

Figure 2 Endoscopic view of the right atrium. Shown are the choroid plexus (CP), the hippocampus $(H)$, the ostium of the temporal horn (arrowhead), and the edge of the endoscope (arrows).

incision is made over one occipital hemisphere and a small burr hole ( $8-15 \mathrm{~mm}$ in diameter) is made just large enough to pass a peel away sheath through which the endoscope is placed. Using stereotactic guidance, the endoscope is advanced into the atrium of the ipsilateral lateral horn and the ostium of the temporal horn identified visually (fig 2 ).

Identification of the choroid plexus and direction of the vertex helps in determining the ostium of the temporal horn versus the frontal horn (fig 2 ). The semi-flexible electrode is then advanced through the lumen of the endoscope and directed down into the temporal horn. As the temporal horn is smaller in diameter than the endoscope and has a curved shape, the electrode is advanced into the temporal horn without advancing the rigid endoscope further than the atrium. Mild resistance occurs in passing the electrode when the tip of the electrode is at the end of the temporal horn (fig 3). Once it is felt that the electrode array is in a satisfactory position, the endoscope is removed and the peel away sheath is removed. The wound is then closed and the electrode secured to the scalp. The procedure is repeated on the opposite side if indicated. Confirmation of electrode position within the middle fossa can be made intraoperatively with a lateral skull radiograph or postoperatively with $\mathrm{CT}$.

The IVEs were typically removed at the bedside once monitoring was finished or just before incision for resective surgery. In two cases, the electrode was left in place to visually confirm electrode location within the temporal horn on the side of the resection.

\section{RESULTS}

A total of eight patients underwent either unilateral or bilateral intraventricular electrode placement. Table l summarises the information for each case. The IVE was crucial for localisation in one patient who had clear seizure onset seen only in one IVE electrode (fig 4). Details of this patient are presented below. The IVE helped localisation in four other patients. We observed reversal of polarity of epileptiform as well as ictal activity between the IVE and the ipsilateral foramen ovale or subdural electrodes in three cases (fig 5). Based on information obtained from invasive monitoring, surgery was offered to seven patients. Of the patients undergoing surgery, one patient underwent a selective amygdalohippocampectomy, one patient underwent 


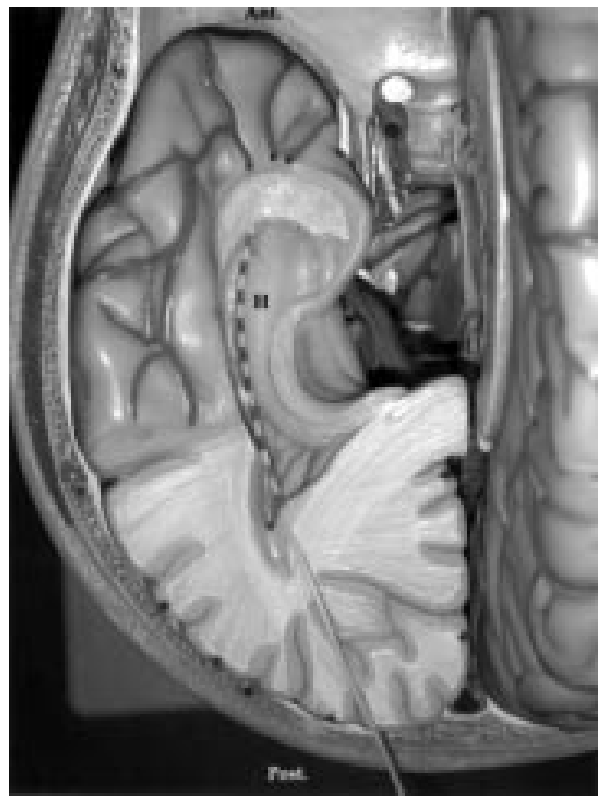

Figure 3 Model representation of placement of intraventricular electrode. Demonstration of intraventricular electrode seen in a cutaway view of the left temporal lobe in a brain model in which the residual left hemisphere is viewed from above. Note relative position of the IVE along the lateral margin of the hippocampus in the temporal lobe.

lesionectomy, and five patients underwent anterior temporal lobectomy and amygdalohippocampectomy. One patient was not offered surgery because of an extra-temporal seizure focus.

In two patients undergoing resective surgery, the electrode was visually seen within the temporal horn abutting the hippocampus at the time of exposure of these structures. No contusions or injuries were noted in adjacent structures, and the electrode tip was located within the rostral end of the temporal horn.

There were no deaths associated with any of the procedures. One patient experienced a small contusion in the thalamus

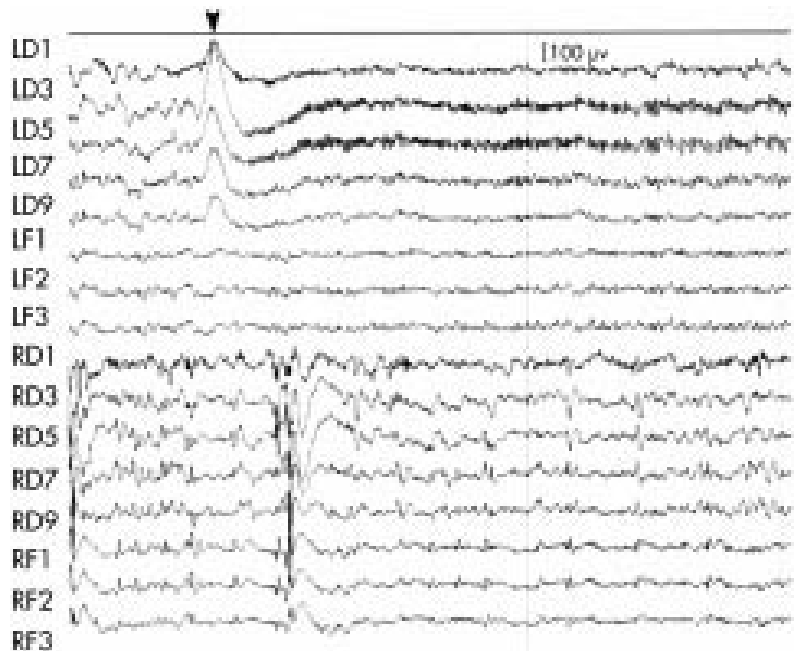

Figure 4 Selected EEG recording obtained from intraventricular electrode showing seizure onset. Depicted is an ictal onset only seen in the left intraventricular electrode (arrowhead). LD, left depth (IVE); $L F$, left foramen ovale; RD, right depth (IVE); RF, right foramen ovale.

presumably from an errant electrode tip. She experienced mild, transient hemiparesis but quickly recovered to full strength. Early in the series, an IVE was postoperatively discovered to have been misguided into the frontal horn of the lateral ventricle instead of the temporal horn. As a result of this, we changed our technique to include an intraoperative lateral skull radiograph to confirm temporal horn placement. One IVE placement was aborted because of difficulty with endoscopic visualisation.

\section{Case discussion}

A 32 year old woman presented with a history of partial onset seizures since childhood. She continued to have seizures on a regimen of phenytoin and lamotrigene. She had no other medical history and had no prior invasive intracranial procedures. She was evaluated with video-EEG monitoring

Table 1 Summary of eight patients undergoing invasive monitoring for epilepsy

\begin{tabular}{|c|c|c|c|c|c|c|c|}
\hline Patient & $\begin{array}{l}\text { Age/ } \\
\text { t sex }\end{array}$ & $\begin{array}{l}\text { Invasive monitoring } \\
\text { performed }\end{array}$ & Resective surgery performed & $\begin{array}{l}\text { Electrode of } \\
\text { seizure onset }\end{array}$ & $\begin{array}{l}\text { Role of IVE in localising } \\
\text { seizure onset }\end{array}$ & $\begin{array}{l}\text { Post-op } \\
\text { Engel } \\
\text { classification }\end{array}$ & $\begin{array}{l}\text { Complication of } \\
\text { IVE placement }\end{array}$ \\
\hline 1 & $46 \mathrm{~F}$ & $\begin{array}{l}\text { left frontal SDGE } \\
\text { left subtemporal SDGE } \\
\text { left IVE }\end{array}$ & $\begin{array}{l}\text { left anterior temporal lobectomy } \\
+\mathrm{AHC}\end{array}$ & Subtemporal SDGE & $\begin{array}{l}\text { Frequent epileptiform } \\
\text { discharges. } \\
\text { IVE did not help in } \\
\text { localising. }\end{array}$ & 1 & $\begin{array}{l}\text { Left thalamic } \\
\text { contusion }\end{array}$ \\
\hline 2 & $23 \mathrm{~F}$ & $\begin{array}{l}\text { bilateral temporal SDSE } \\
\text { bilateral IVE }\end{array}$ & $\begin{array}{l}\text { right anterior temporal } \\
\text { lobectomy }+\mathrm{AHC}\end{array}$ & $\begin{array}{l}\text { Simultaneous: } \\
\text { - Right IVE } \\
\text { - Right subtemporal } \\
\text { SDSE }\end{array}$ & $\begin{array}{l}\text { Dipole between right } \\
\text { subtemporal SDSE and right } \\
\text { IVE. }\end{array}$ & 1 & $\begin{array}{l}\text { IVE placed into } \\
\text { frontal horn on } \\
\text { left side }\end{array}$ \\
\hline 3 & $32 \mathrm{~F}$ & $\begin{array}{l}\text { bilateral FOE } \\
\text { bilateral IVE }\end{array}$ & left selective $\mathrm{AHC}$ & Left IVE & Localised seizure origin. & 1 & none \\
\hline 4 & $\begin{array}{l}32 \\
M\end{array}$ & $\begin{array}{l}\text { right temporal SDSE } \\
\text { left FOE } \\
\text { bilateral IVE }\end{array}$ & $\begin{array}{l}\text { right anterior temporal } \\
\text { lobectomy }+\mathrm{AHC}\end{array}$ & $\begin{array}{l}\text { Right subtemporal } \\
\text { SDSE }\end{array}$ & $\begin{array}{l}\text { Noted dipole formed } \\
\text { between right anterior SDSE } \\
\text { and anterior IVE. }\end{array}$ & 1 & none \\
\hline 5 & $\begin{array}{l}23 \\
M\end{array}$ & $\begin{array}{l}\text { left frontal SDGE } \\
\text { left temporal SDGE } \\
\text { left IVE }\end{array}$ & $\begin{array}{l}\text { left anterior temporal lobectomy } \\
+\mathrm{AHC}\end{array}$ & $\begin{array}{l}\text { Left subtemporal } \\
\text { SDGE }\end{array}$ & - & $\|^{*}$ & Aborted IVE. \\
\hline 6 & $\begin{array}{l}28 \\
M\end{array}$ & $\begin{array}{l}\text { right FOE } \\
\text { left subtemporal SDGE } \\
\text { bilateral IVE }\end{array}$ & $\begin{array}{l}\text { left temporal seizure-focus } \\
\text { resection }+\mathrm{AHC}\end{array}$ & $\begin{array}{l}\text { Simultaneous: } \\
\text { - Left IVE } \\
\text { - Left subtemporal } \\
\text { SDGE }\end{array}$ & $\begin{array}{l}\text { IVE revealed frequent } \\
\text { epileptiform discharges in } \\
\text { the posterior electrode. }\end{array}$ & 1 & none \\
\hline 7 & 18 & $\begin{array}{l}\text { bilateral SDSE } \\
\text { bilateral IVE }\end{array}$ & $\begin{array}{l}\text { no surgery offered - } \\
\text { non-temporal focus }\end{array}$ & $\begin{array}{l}\text { Bilateral posterior } \\
\text { SDSE }\end{array}$ & $\begin{array}{l}\text { No ictal discharge recorded } \\
\text { in IVEs }\end{array}$ & - & none \\
\hline 8 & $21 \mathrm{~F}$ & $\begin{array}{l}\text { right FOE } \\
\text { right IVE } \\
\text { right SDGE }\end{array}$ & $\begin{array}{l}\text { right anterior temporal } \\
\text { lobectomy + AHC }\end{array}$ & $\begin{array}{l}\text { Simultaneous: } \\
\text { - Right FOE } \\
\text { - Right IVE }\end{array}$ & $\begin{array}{l}\text { Found dipole between FOE } \\
\text { and IVE. }\end{array}$ & 1 & none \\
\hline
\end{tabular}

FOE, foramen ovale electrode; IVE, intraventricular electrode; SDGE, subdural grid electrode; SDSE, subdural strip electrode; AHC, amygdalohippocampectomy. *Alcohol related seizure postoperatively. 


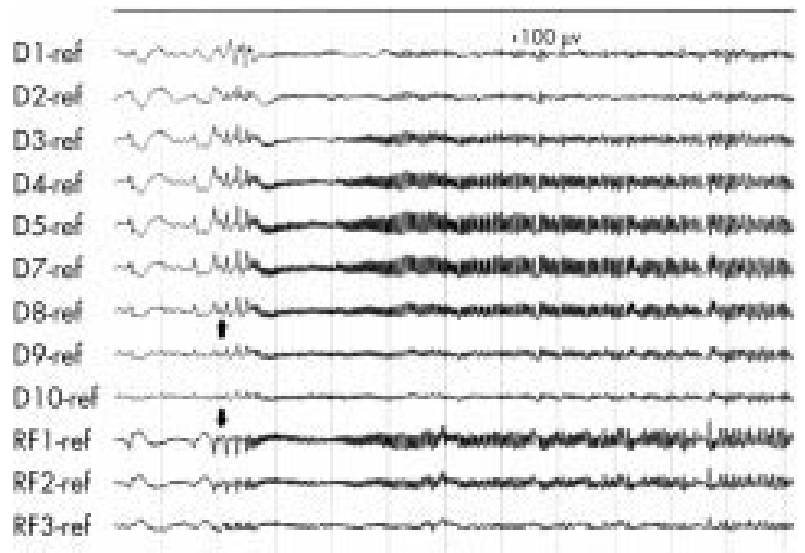

Figure 5 Selected EEG recording from another patient showing reversal of polarity between the intraventricular electrode and the foramen ovale electrode on the right side (arrows). D, right depth (IVE); RF, right foramen ovale.

and intravascular amytal testing (WADA test). This revealed that she had predominant language and memory on her right side but also appeared to have independent bilateral temporal seizure foci. MRI did not reveal any obvious mesial temporal sclerosis or other structural abnormality.

To investigate her further, she initially underwent placement intraoperatively of bilateral foramen ovale electrodes and bilateral intraventricular electrodes. This occurred without complication and after spending one night in the intensive care unit, she was transferred to the epilepsy unit for monitoring. During this time, she exhibited several seizures that could be localised from the implanted electrodes (fig 4). Once monitoring satisfactorily determined her seizure focus, the foramen ovale and intraventricular electrodes were removed. One week after the initial operation she underwent a selective amygdalohippocampectomy. She recovered fully and currently is seizure free with treatment 36 months postoperatively.

\section{DISCUSSION}

We have described a technique for placement of intraventricular electrodes for monitoring of mesial temporal lobe epilepsy. This technique has been used in seven of eight patients with good results and has provided useful data in assisting in planning surgery for resection of mesial compared with other temporal structures associated with seizure foci. Review of the literature reveals a previous study by Blume et al, ${ }^{8}$ reporting the results of a multicontact electrode array stereotactically placed into the temporal horn of the lateral ventricle. They also report good data from the intraventricular recordings but do not describe the technique in detail.

Currently, there are two other reported methods for intraparenchymal monitoring of seizures from the mesial temporal lobe. Orthogonal depth electrodes are placed perpendicularly through the parenchyma of the temporal lobe from the lateral temporal surface. This method has been used with good effect and provides useful information. However, it is limited in that it provides data from only a very small area adjacent to each depth electrode. With this technique, multiple depth electrodes are required to span the length of the hippocampus. Furthermore, the risk of injuring a blood vessel increases with each pass. ${ }^{5}$ Longitudinal or occipital depth electrodes are also used to monitor seizures originating from the amygdala and hippocampus and are well described. ${ }^{11}{ }^{12}$ However, it is difficult to locate all contacts of the electrode in both the amygdala and hippocampus and placement could produce injury in the non-epileptogenic hippocampus. In fact, it has also been proposed that interictal slow wave changes recorded from parenchymally located depth electrodes may represent non-specific tissue injury caused by their placement. ${ }^{5}$

We are able to advance the electrode array to the end of the temporal horn to closely abut and span the amygdala and hippocampus without injuring the tissue we are monitoring. We have found that these recordings are at least as useful as traditional depth electrodes. It is important to note that while these electrodes are ideal for spanning the length of the mesial temporal lobe and can help lateralise seizures, they alone cannot distinguish between mesial and lateral temporal or extratemporal seizure onsets without other forms of invasive monitoring (for example, subdural strips/grids, foramen ovale electrodes, other depth electrodes).

One potential problem with placing electrodes into the CSF is pulsation artefact and the quality of the recordings. We did not observe any degradation in our recordings from the IVEs compared with signals obtained from other implanted electrodes within the same patient. Another potential problem is the possibility that the electrode would not be held against the hippocampus in patients with enlarged temporal horns. Lastly, we had to abort one procedure because of poor endoscopic visualisation bringing up the concern that this procedure may be more difficult or impossible in patients with small ventricles. At this time, we cannot say whether small or enlarged ventricles will present a problem in the future.

In the technique described in this paper, we theorised that we could tackle the problems of adequate electrode coverage, risk of vascular injury, and avoidance of tissue injury. While there is a comparatively steep learning curve for the procedure, we have not had any serious permanent complications associated with the placement of the IVEs. One instance of thalamic contusion was experienced-in the future, we may attempt to record electrical impedance from the distal electrode contacts to determine if we are in CSF or parenchyma. We also describe one complication in our series involving misplacement of an IVE into the frontal horn early in the series. Based on this, our technique has evolved and lateral skull radiographs are now routinely performed intraoperatively. There is a risk for haemorrhagic complications, especially involving the choroid, and occipital lobe injury, as with longitudinal depth electrodes, but so far we have not encountered any and do not feel that it is any greater than with placement of a single depth electrode and is less than multiple depth electrodes placed in each temporal lobe.

Authors' affiliations

B Abou-Khalil, Department of Neurology, Vanderbilt University Medical Center, Nashville, Tennessee, USA

J K Song, P E Konrad, Department of Neurosurgery, Vanderbilt

University Medical Center

Funding: none

Competing interests: none declared

\section{REFERENCES}

1 Nakase $\mathbf{H}$, Ohnishi $\mathrm{H}$, Touho $\mathrm{H}$, et al. An intra-arterial electrode for intracranial electro-encephalogram recordings. Acta Neurochir 1995; 136:103-5

2 Behrens E, Zentner J, van Roost D, et al. Subdural and depth electrodes in the presurgical evaluation of epilepsy. Acta Neurochir 1994;128:84-7.

3 Spencer SS, Spencer DD, Williamson PD, et al. Combined depth and subdural electrode investigation in uncontrolled epilepsy. Neurology 1990;40:74-9.

4 Risinger $\mathbf{M}$. Electroencephalographic strategies for determining the epileptogenic zone. In: Luders H, ed. Epilepsy surgery. New York: Raven Press, 1992:337-47

5 So $\mathbf{N}$. Depth electrode studies in mesial temporal lobe epilepsy. In: Luders H, ed. Epilepsy surgery. New York: Raven Press, 1992:371-84.

6 Ross D. Intracerebral depth electrode monitoring in partial epilepsy: the morbidity and efficacy of placement using magnetic resonance image-guided stereotactic surgery. Neurosurgery 1996;39:327-33. 
7 Cahan L, Sutherling W, McCullough M. Review of the 20 year UCLA experience with surgery for epilepsy. Cleve Clin J Med 1984;51:313.

8 Blume WT, Parrent AG, Kaibara M. Stereotactic

amygdalohippocampotomy and mesial temporal spikes. Epilepsia 1997:38:930-6.

9 Polkey CE, Binnie CD, Janota I. Acute hippocampal recording and pathology at temporal lobe resection and amygdalo-hippocampectomy for epilepsy. J Neurol Neurosurg Psychiatry 1989;52:1050-7.
10 McBride MC, Binnie CD, Janota l, et al. Predictive value of intraoperative electrocorticograms in resective epilepsy surgery. Ann

11 McCarthy G, Spencer D, Riker R. The stereotactic placement of depth electrodes in epilepsy. In: Luders $\mathrm{H}$, ed. Epilepsy surgery. New York: Raven Press, 1992:385-93.

12 Blatt DR, Roper SN, Friedman WA. Invasive monitoring of limbic epilepsy using stereotactic depth and subdural strip electrodes: surgical technique. Surg Neurol 1997;48:74-9.

\section{NEURONLINE}

\section{Web based neurology "textbooks": www.medlink.com and www.emedicine.com/neuro}

M edlink (www.medlink.com) and eMedicine (www.emedicine.com/ neuro) tout themselves as comprehensive web based neurology "textbooks". Medlink is a US based service devoted solely to neurology. It has the disadvantage of a hefty fee for access: $\$ 416$ annually (or \$319 if you agree to view adverts). On the plus side you receive a $\mathrm{CD}$ updated quarterly-copy this to your laptop's hard drive and you can carry around a textbook that contains about 1000 articles (with a total word count I estimate at over double Bradley's Neurology in clinical practice). Furthermore, the site and CD include pictures and over 100 videos. There is no annoying bar on copying these or the text, so a multimedia presentation on the neurological topic of your choice can be prepared, in theory at least, in minutes. Searching for articles is straight forward, and each topic is laid out in the same logical order. Further attractions include web forums, patient information leaflets, and a news section.

eMedicine is also a US based site, but in contrast encompasses the whole of clinical medicine. The service, in its basic form (restricted access to pictures), is free, although you have to suffer banner adverts and a registration procedure. In length and format comparable to Medlink, 384 neurology topics are listed, but in general with superior information on treatment.

To evaluate these sites I picked on some issues raised from recent consultations: the management of migraine in pregnancy, the switching of anticonvulsants, the third line management of essential tremor, and the clinical diagnosis of subarachnoid haemorrhage. Secondly, I assessed the information on a number of rare disorders I have encountered in the past few months: familial episodic ataxia

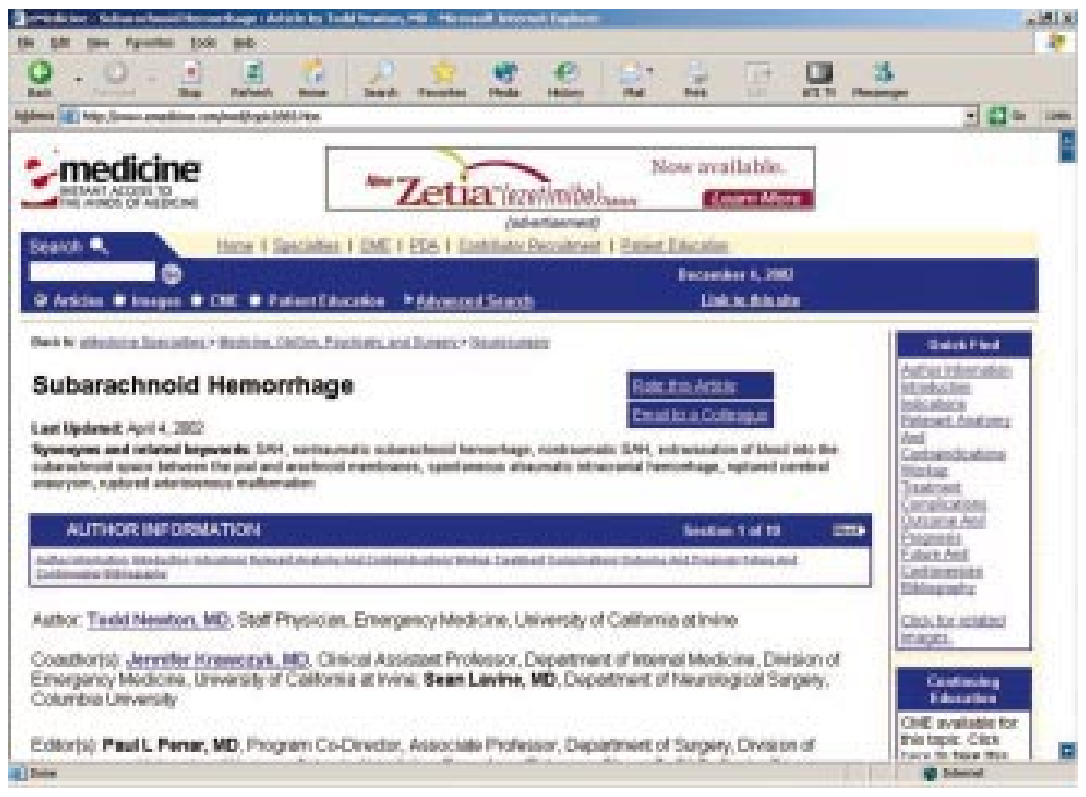

Hallervorden-Spatz syndrome, and hemimasticatory spasm.

The rarities were dealt with relatively well by both sites, although the referencing and, to a lesser extent, the depth of material was better at Medlink. It was disappointing that neither suggested the correct spelling (as "Google" would) when "Hallevorden" was entered, although surprisingly eMedicine did come up with two related articles containing this mistake. The treatment of migraine in pregnancy was not specifically discussed by either site, although eMedicine provided some information. Medlink also failed to provide useful advice on switching anticonvulsants, whereas eMedicine did at least give specific guidance on speed of withdrawal. The management of essential tremor was dealt with in depth by both services, with eMedicine, in contrast to Medlink, giving pragmatic guidance for situations where evidence is lacking. The difficult,but common, issue of clinically distinguishing subarachnoid haemorrhage from a benign headache was not addressed by either site. Furthermore, Medlink did not mention spectrophotometry and eMedicine did not discuss the evidence (or lack of it) for the use of this test. These criticisms should not detract from the fact that these sites are impressive resources that should be commended for what they have achieved. And the future? Hopefully an even more comprehensive resource, including high quality video, no banner adverts, and no fee. A challenge, perhaps, for national/international neurological associations in the digital age?

M Zeidler

Victoria Hospital, Hayfield Road, Kirkcaldy, Fife KY2 5AH; martinz@globalnet.co.uk jnjunnl.s 1 